\title{
Detection of metastatic calcification in lungs and stomach with radionuclide in multiple myeloma
}

\author{
F CARDELLACH, J RABASSEDA, A PUJOL, F LOMEÑA, M INGELMO, A BALCELLS GORINA \\ From the Catedra de Patologia General, Servicio de Anatomía Patologica, and Servicio de Isotopos Radiactivos, \\ Hospital Clinico y Provincial, University of Barcelona, Barcelona, Spain
}

Metastatic calcification is commonly associated with multiple myeloma, presumably because this disorder has a propensity for causing hypercalcaemia and renal failure. Pathologically, the most common sites of calcium deposition are the lung, kidney, gastric mucosa, heart, and blood vessels.' Metastatic pulmonary calcification is rarely detected radiographically, and when it is other pulmonary abnormalities (most often caused by infections) must be ruled out. ${ }^{2}$ Some authors ${ }^{14}$ have emphasised the clinical value of routine bone scans to detect interstitial pulmonary calcification, and to study the effects of treatment. This report describes a patient with multiple myeloma in whom the bone scan showed metastatic calcification in the lungs and stomach.

\section{Case report}

A 55-year-old-man was well until three months before admission, when he developed left costal pain. He was admitted to the hospital because of a persistent low back pain that had appeared acutely one month previously. Blood pressure was $165 / 100 \mathrm{~mm} \mathrm{Hg}$, pulse 88 beats $/ \mathrm{min}$; temperature $36 \cdot 2^{\circ} \mathrm{C}$. The chest was clear; the liver was palpable $2 \mathrm{~cm}$ below the costal margin. There was a solid palpable mass in the left mid axillary line. Laboratory studies gave the following results: erythrocyte sedimentation rate $56 \mathrm{~mm}$ in one hour; erythrocyte count $4.43 \times$ $10^{12} / 1$; leucocyte count, $8.2 \times 10^{9} / 1$, haematocrit $40.8 \%$; calcium $14.6 \mathrm{mg} / 100 \mathrm{ml}(3.65 \mathrm{~mm} / \mathrm{l})$; phosphorus $3.4 \mathrm{mg} /$ $100 \mathrm{ml}(1.1 \mathrm{mmol} / 1)$; blood urea nitrogen $45 \mathrm{mg} / 100$ $\mathrm{ml}$ (32.1 mmol/l); creatinine $3.1 \mathrm{mg} / 100 \mathrm{ml}$ (274 $\mu \mathrm{mol} / \mathrm{l})$. Bone marrow aspiration showed $12 \%$ of mature plasma cells and the diagnosis of multiple myeloma, IgA lambda type, was confirmed by urine and serum immunoelectrophoresis. Abdominal films were normal. Bone films disclosed multiple lytic lesions in the skull, ribs, pelvis, and spine. Chest radiography revealed diffuse interstitial pulmonary nodularity and a myelomatous tumour in the left chest wall. The transfer coefficient (KCO) was reduced to $71 \%$ of predicted normal, transfer factor being $55 \%$ of predicted. Spirometry gave normal results.

A bone scan was performed with $10 \mathrm{mCi}$ of $99 \mathrm{~m} \mathrm{Tc}$ polyphosphate. Results indicated skeletal lesions and unusual uptake of the radionuclide in the lungs and

Address for reprint requests: Dr F Cardellach, Catedra de Patologia General, Hospital Clinico y Provincial, Casanova 143, Barcelona-36, Spain. stomach (fig 1). Results of a repeat study performed two months later were identical. Despite intensive treatment the patient died 15 days after the second scintigraphic examination.

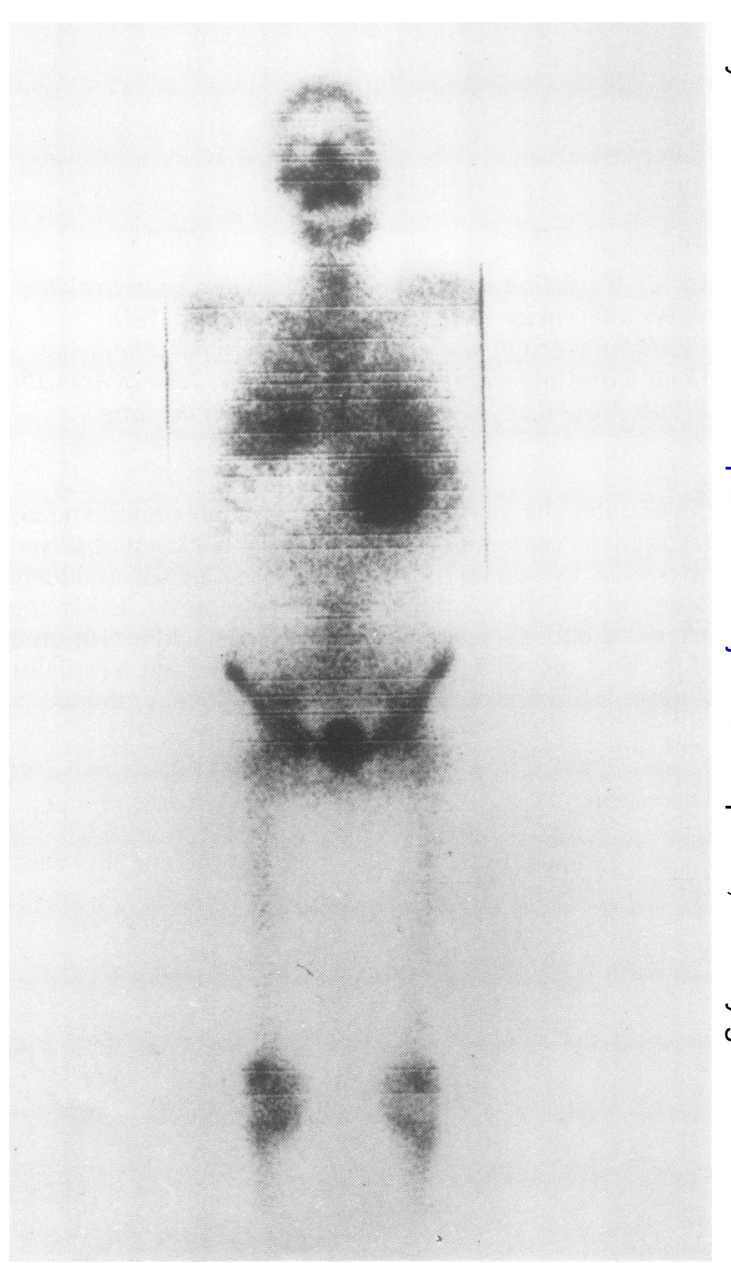

Fig 1 Anterior view of bone scan with ${ }^{99 m}$ Tc-polyphosphate showing increased uptake in the lungs and stomach. 


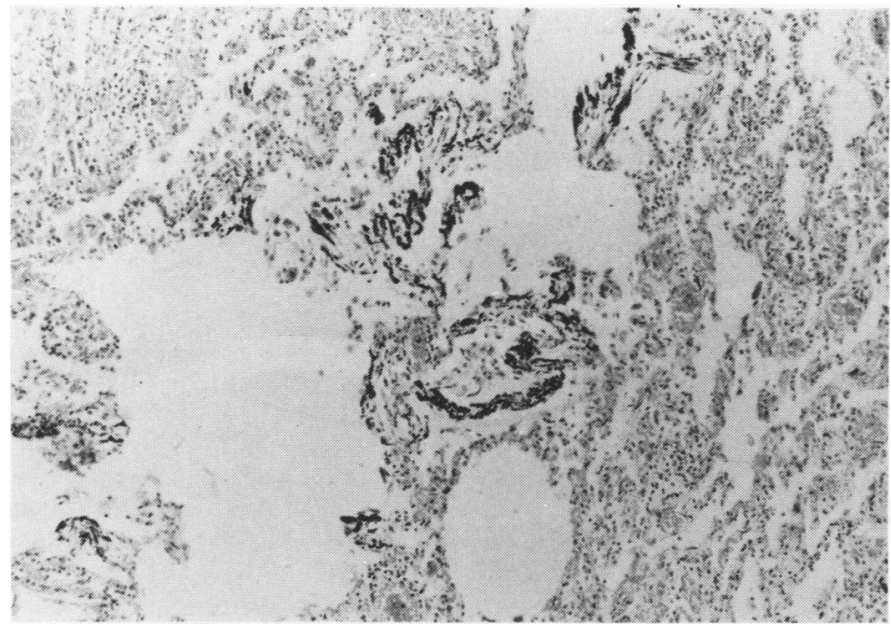

Fig 2 Photomicrograph of lung showing diffuse calcification in alveolar septa ( $H$ and $E \times 200)$.

Postmortem examination disclosed diffuse metastatic calcification in the alveolar septa (fig 2), kidneys, gastric mucosa, blood vessels, and tendons. Specific stains for amyloid were negative.

\section{Discussion}

Although metastatic calcification in lung and gastric mucosa is commonly seen in tissue examinations of patients with multiple myeloma, ${ }^{1}$ radiographic evidence is rarely present. In the review by Kintzer et $a^{2}$ only 95 of 958 cases $(10 \%)$ of multiple myeloma had recognisable pulmonary infiltrations (4\% as the initial manifestation). The majority (71) were localised, unilateral or bilateral, and the remaining 24 patients had a diffuse pulmonary infiltrate, as in our patient, but none showed calcification. Grames et $a l^{1}$ described two patients with hypercalcaemia, one with multiple myeloma and the other with metastatic carcinoma, who showed striking concentrations of boneseeking radiopharmaceuticals (technetium-99m) in the lungs and on routine bone scans. Neither had pulmonary infiltrates on chest films. Valdez et $a l^{4}$ reported another patient with multiple myeloma and associated intense radionuclide uptake in the lungs and stomach on bone scan, but with a normal chest radiograph.
The patient we describe showed diffuse interstitial pulmonary shadowing, presumably due to metastatic calcification as the necropsy showed no amyloidosis or other disease. We agree with the suggestion ${ }^{1}$ that the early detection of extraskeletal calcification by boneseeking radionuclides in patients with multiple myeloma probably provides a unique opportunity to study metastatic calcification and the effects of treatment. Moreover, it should be an aid in the differential diagnosis of diffuse pulmonary infiltrates in these patients.

\section{References}

' Grames GM, Sauser DD, Jansen C, Soderblam RE, Hodgkin JE, Stilson MS. Radionuclide detection of diffuse interstitial pulmonary calcification. JAMA 1974;230:992-5.

${ }^{2}$ Kintzer JS, Rosenow EC, Kyle RA. Thoracic and pulmonary abnormalities in multiple myeloma. A review of 958 cases. Arch Intern Med 1978;138:727-30.

${ }^{3}$ Kapadia SB. Multiple myeloma: A clinicopathologic study of 62 consecutively autopsied cases. Medicine (Baltimore) 1980;59:280-92.

4 Valdez VA, Jacobstein JG, Perlmutter S, Brusman H. Metastatic calcification in lungs and stomach demonstrated on bone scan in multiple myeloma. Clin Nucl Med 1979;4:120-1. 